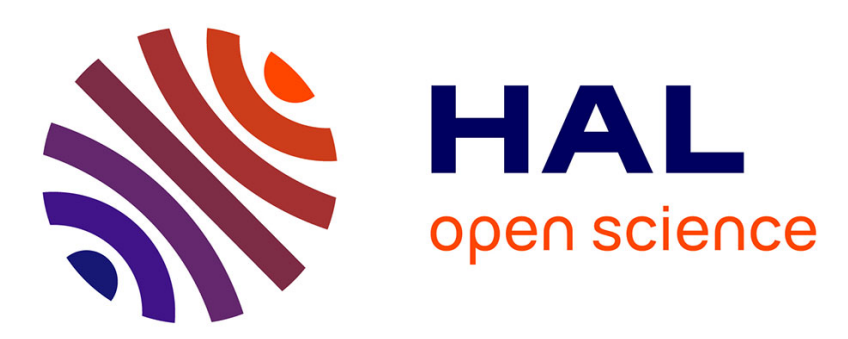

\title{
Little less conversation, little more action: Musical intervention as aesthetic material communication
}

\author{
Virpi Sorsa, Heini Merkkiniemi, Nada Endrissat, Gazi Islam
}

\section{To cite this version:}

Virpi Sorsa, Heini Merkkiniemi, Nada Endrissat, Gazi Islam. Little less conversation, little more action: Musical intervention as aesthetic material communication. Journal of Business Research, 2018, 85, pp.365-374. halshs-01959027

\section{HAL Id: halshs-01959027 https://shs.hal.science/halshs-01959027}

Submitted on 18 Dec 2018

HAL is a multi-disciplinary open access archive for the deposit and dissemination of scientific research documents, whether they are published or not. The documents may come from teaching and research institutions in France or abroad, or from public or private research centers.
L'archive ouverte pluridisciplinaire HAL, est destinée au dépôt et à la diffusion de documents scientifiques de niveau recherche, publiés ou non, émanant des établissements d'enseignement et de recherche français ou étrangers, des laboratoires publics ou privés. 
running head: Musical intervention as aesthetic material communication

Little less conversation, little more action: Musical intervention as aesthetic material communication

Sorsa, V. Merkkiniemi, H., Endrissat, N \& Islam, G. (2018). Little less conversation, little more action: Musical intervention as aesthetic material communication. Journal of Business Research,85, 365-374.

\begin{abstract}
While interest in art-based interventions is growing rapidly, little is known about the aesthetic, material, and interpersonal mechanisms by which art interventions, and musical interventions in particular, operate. We address this gap by drawing from an in-depth case study of a musical intervention in a professional ice-hockey team in Finland. At the time of the study, the organization faced a serious crisis, having lost 11 sequential games, leading its managers to search for "alternative" means for promoting social cohesion, and subsequently engaging in an arts-based musical intervention. Our findings examine how material objects and collective synchronization rhythms grounded the interpersonal interactions of team members and mediated members' attempts to transform personal subjective experiences into collective collaboration. We draw out the conceptual implications of our findings for understanding, on the one hand, the collective nature of aesthetic processes, and on the other hand, the materially mediated processes of communication. In terms of practical implication, we contribute to understanding the social dynamics and transformative organizational possibilities of artistic interventions that generate value for the organization and its members.
\end{abstract}

Keywords: arts-based intervention, musical intervention, aesthetics, embodied communication, materiality, organizational communication

Funding: This work was supported by The Finnish Work Environment Fund 


\section{Little less conversation, little more action: Musical intervention as aesthetic material communication}

Music, deeply affecting experience, can communicate beyond words; embodied and intimate, it can be used to elicit responses and turn "apathy to action" (Adler \& Ippolito, 2016: 23). Both immediately perceivable and intangible, music simultaneously reflects "material conditions and social relations" (Styhre, 2008: xvii). Melodies elicit a broad spectrum of experience, constituting articulation points between individual and collective experience and embodying the rhythms of collective work (Korczynski, Pickering \& Robertson, 2008). Organizational scholarship has acknowledged the power of music (e.g. Nissley, 2002; Prichard et al., 2007) including its direct effects on work (e.g., El-Sawad \& Korczynski, 2007; Jones $\&$ Schumacher, 1992) and the role of musical performance by workers (Korczynski, 2003; Korczynski et al., 2005; Nissley, 2002). The latter notes music's transformative power for social bonds and community-building, resonating with what Mattern (1998) terms 'acting in concert', a metaphor emphasizing community-based political action through music.

As part of a larger trend towards artistic projects and artful interventions in organizations (e.g. Berthoin Antal, 2013; Meisiek \& Hatch, 2008; Taylor \& Ladkin, 2014), musical interventions highlight empowerment, engagement, and exploration (Adler \& Ippolito, 2016; Small, 1998). While interest in arts-based interventions is growing rapidly among both scholars and practitioners (Schiuma, 2011), little is known about the aesthetic, material, and interpersonal mechanisms by which art interventions operate. Some argue that 'bringing art to work' provides organizational members with unusual experiences to initiate and facilitate organizational learning and change (Berhoin Antal \& Strauss, 2014; Taylor \& Ladkin, 2009), while studies of 
arts-based knowing (e.g. Barry \& Meisiek, 2010; Schiuma, 2011) link aesthetic experience in art to organizational practice. In their review, Meisiek and Barry (2014) conclude that empirical illustrations of artistic interventions are mostly anecdotal, calling for more thorough theoretical and empirical research to understand the effects of such interventions.

We address this call by examining the interface of aesthetic experience and collective interaction in musical interventions. Taking a communication-based perspective, we address the problem of how deeply personal aesthetic experiences can support team interaction and ground collective phenomena. Specifically, our research question asks how musical interventions mobilize embodied and aesthetic experiences to support collective communication processes.

Empirically, we draw from an in-depth case study of a musical intervention in a professional ice-hockey team in Finland. At the time of the study, the organization faced a serious crisis, having lost 11 sequential games, leading its managers to search for "alternative" means to promote cohesion, and they decided to engage in an artsbased musical intervention. We followed the team through the intervention process by collecting video-recorded real-time data, interviews and discourse from an online forum. Our findings trace the musical intervention process to illustrate a.) The team's difficulty in articulating its coordination process in traditional forms, b.) The uses of material instruments and artefacts to provide channels of aesthetic experience and expression, and c.) The synchronization processes that supported interpersonal communication among team members. Team interactions were supported by material (human-instrument relation) and collective (interpersonal synchronization) processes that mutually supported each other. We propose that the aesthetic, material, and interpersonal aspects were entangled in a process we refer to as embodied 
communication, a concept mobilized to explain arts-based interventions' ability to promote new forms of experience and organizing.

Our research contributes to understanding the social dynamics of collective interaction around aesthetics and materiality, with the ultimate goal of understanding the transformative possibilities of arts-based, and specifically musical, interventions within organizations. By exploring the effects of art we contribute to aesthetic understandings of art-based interventions (cf. de Monthoux \& Statler, 2008). Moving from individual aesthetic experience to collective communicative processes, we argue, relates to diverse organizational and business contexts. Additionally, we contribute to the communicative constitution of organizations $(\mathrm{CCO})$ perspective (e.g. Ashcraft, Kuhn \& Cooren, 2009; Cooren, Kuhn, Cornellissen, \& Clark, 2011; Putnam \& Nicotera, 2009) by linking aesthetics with communicative processes, a theoretical interface between aesthetics and communication that is underdeveloped in current literature.

The rest of the paper unfolds as follows: After synthesizing current work in artistic interventions from aesthetic and communicative lenses, we describe our empirical case as an organizational crisis involving difficulties in team coordination, as the background to our study. Next, outlining our methods and analytical approach we present our findings in terms of the difficulties in articulation as well as material and collective interactions constituting the intervention. Finally, we draw out the conclusions for understanding musical interventions in organizations, drawing implications for future research across diverse organizational contexts. 


\section{Theoretical framework}

\subsection{Aesthetic experiences in artistic interventions: from subjective experience to}

collective collaboration

Aesthetic experiences are constitutive for organizational functioning (Strati, 1992; Strati \& Montoux, 2002; Taylor \& Hanson, 2005). Team coordination and dynamics, for example, have been shown to rely on shared aesthetic experiences among team members (Endrissat, Islam, \& Noppeney, 2016; Ewenstein \& Whyte, 2007). Aesthetic experience is both deeply personal, involving an embodied sense of meaning (Warren, 2008), but also constitutive of social norms and expectations, as members expect others to feel as they do (Martin, 2002).

Although aesthetic experience has a collective component and is essential to collective processes, it is notoriously difficult to express (Ewenstein \& Whyte, 2007), and relies on particular communicative forms in its articulation (Toraldo, Islam, \& Mangia, 2016). Difficult to put in words or concepts, it eludes logical formulation and is sensed rather than communicated. Aesthetic experience is closely linked to experiential knowing, informed by the immediacy of felt sense, through empathy and resonance (Taylor \& Hansen, 2005: 1212/1213). Organizations struggle to create conditions for shared aesthetic experience, encountering difficulty in articulating such experience that has been referred to as "aesthetic muteness" (Taylor, 2002).

The increasing attention to artistic interventions has arisen, in part, in response to the need for organizational members to explore aspects of organizing that are difficult to articulate in everyday discourse. Aesthetic experiences through artistic interventions and arts-based knowing (Schiuma, 2011) link to organizational practice by provoking, edifying or irritating long-held and often dysfunctional beliefs among 
organizational members (Barry \& Meisiek, 2010: 1512). Artistic interventions enable 'context shifting' where the focus is on "experiencing aspects of the workplace through another medium", such as theatre or music. Artistic interventions provide an embodied experience, a 'felt sense' of what is going wrong or what is needed on the collective level (Taylor \& Ladkin, 2009). For example, improvisation exercises can help managers "to feel what it is like to listen deeply and be listened to deeply" (Ibid., p. 64). Insights like this provide anchors that help to address and change work practices and transform negative dynamics at the workplace.

Musical interventions seem particularly suitable to improve awareness of self and others (Blunt, 1994), which is essential for collaborative dialogue (Furu, 2012). Research in the field of organization and management studies has shown music's ability to establish relationships and to build communities (Korczynski, 2003; Korczynski et al., 2005). For example, organizational songs are both a sign and artefact of community and an "aid in the creation of community" (Nissley, 2002: 59). Through music, commonalities can be created and discovered to establish social bonds and community-building that allows people to 'act in concert' (Mattern, 1998 cited in Nissley, 2002: 59). For instance, Adler \& Ippolito (2016) examined how musical interventions can constitute what they call "poetic activism", rebuilding community bonds in the face of collective trauma. Marotto, Roos, and Victor (2007) consider how individual aesthetic experiences translate into collective peak performance. Building on the insight that stories can be 'shared, built upon (chained), and dramatically transform a group" (Turner, 1974, p. 389), the authors theorize how performing music collectively establishes shared aesthetic experience (similar to collective mystical or religious experiences, ibid. p. 390) that creates a sense of communitas. Communitas is 'a flash of lucid mutual understanding on the existential 
level when participants feel that all problems, not just their problems, could be resolved ... if only the group as "essentially us" could sustain its intersubjective illumination' (Turner, 1986 - cited in Marotto et al., 2007: 390/391). It is a moment that often coincides with a shared consciousness and an emotional state that stresses the 'we' over the 'I' - as epitomized in comments such as "wwe were one heart ...' or '... we were one“" (Marotto et al. 2007: 408).

Artistic interventions and aesthetic experiences in particular, thus represent a form of communication (Gagliardi, 1996: 566; Nissley, 2002), which can be described as aesthetic interactions and transformations on the collective level (Taylor, 2002). It builds on a collectively felt sense, an aesthetic interaction materially mediated through music reflecting both "material conditions and social relations" (Styhre, 2008: xvii). We argue that this materially mediated aesthetic experience is essential for bridging subjective experience and collective collaboration.

\subsection{Materially mediated communication: Aesthetics and CCO}

One way to bridge subjective experience and collaboration comes from emerging perspectives on the role of materiality in organizational communication. Focusing on the communicative constitution of organizations (CCO, Ashcraft, Kuhn \& Cooren, 2009; Cooren, Kuhn, Cornelissen, \& Clark, 2011; Putnam \& Nicotera, 2009) this literature emphasizes text and discourse as bringing organizations into being (Nicolini, 2012: 189). Organizations are understood as socially constituted with communication as the central interactional event in the accomplishment of organizational activity (Cooren, Vaara, Langley \& Tsoukas, 2014; Nicolini, 2012: 189). CCO scholars draw attention to how organizational activities are generated, renewed and reproduced through interaction and communication (Cooren et al. 2014: $1-5)$. 
Despite CCO's focus on discourse, the continuous work of organizing is not only discursive (Cooren, 2010). Organizing is driven in a specific, material way by objects, artefacts, and other material configurations that support action. A materiality-based understanding of the constitution of organizational activity and practices is important to reflect the organizational phenomena that we "so dearly house ourselves to" (Taylor, 2014: 36). From the communicative perspective, organizational activities and practices such as "innovation," "cooperation," "celebration," and so forth are enabled by our social practices, both in terms of linguistic and discursive conventions (Cooren et al., 2014: 2; Hardy, 2004) but also in the material supports for communicative relations (Cooren, 2015). Studying material processes in this way means re-focusing the analysis from linguistic discourse to how embodied and material artefacts shape action. In sum, analyzing communication involves not only understanding spoken and written language, but also the different beings and materiality that participate in communicative situations.

Analyzing how the plenum of agencies (Cooren, 2006) participates in constituting organizational activities involves focusing on "how people implicitly or explicitly keep invoking, evoking, and convoking various forms of agency in their conversations" (Cooren, 2015: 477). Although recognizing the presence of various agents in communication, the CCO perspective studies communication with a linguistic focus, paying less attention to the material and aesthetic properties of experience and their communicative possibilities (Sorsa, Pälli \& Mikkola, 2014). In this context, examining music as embodied communication provides a useful transition. According to Gagliardi (1996) aesthetic experiences communicate, yet are different from speech. Unlike speech, music is not associated with a fixed semantic system, although it conveys meaning through other systems, such as emotional 
experiences and associative memories. Associative memories are most likely the locus of the semantic priming, and the recent research has shown that music can, as language, determine semantic processing (Koelsch, et al. 2004; Peretz \& Zatorre, 2005). Music as a communicative medium "is not simply an alternative way to say the same things that humans say through speech. Music, like other aesthetic expressions, can express meanings that are not accessible through words or express them in ways that give listeners more immediate access to emotions" (Mattern, 1998: 17, cited in Nissley, 2002: 59). In other words, music has the ability to inform us about both individual and organizational phenomena in a way that is embodied and sensed and not (necessarily) rational-analytic and outspoken (Nissley, 2002). To explore how music informs individual and collective experience, we turn to our empirical case.

\section{Empirical case}

"And well, the intervention worked amazingly well. It is a kind of a fairytale. Even today when the song is played in the locker room the boys start to drum and play and I can see the fun that they have." (Head coach)

Our field study involved a musical intervention applied in a Finnish national league ice-hockey team. Because our interest in artistic interventions involved collective coordination processes in a highly embodied and affectively intense environment, examining a professional sports organization provided an ideal setting for examining these processes. The second author designed and facilitated the intervention, working as a consultant in the coaching team for 6 months. Her role in the process included management consulting and team coaching. The organization faced a crisis based on a continued losing streak, in the context of management changes and new player integration, with frequent conflict. The site's characterization as an "extreme case" (e.g. Flyvberg, 2006) was established by the serious nature of the organizational 
problems and the subsequent post-intervention success, described by the head coach as "a real life fairytale" (see quote above).

The organization had been experiencing what the head coach called a "negative whirlpool" of conflict and eroding performance. Early in the season, the team management had changed several players and also suffered setbacks due to injuries. New players had been recruited, some having just arrived from foreign countries, and one of the key players had left; this reshuffling meant that the managers did not yet have a clear allocation of tasks and positions in the team. During play, the team suffered repetitive penalties due to violence on ice, causing frustration and division among team members. The players, lacking knowledge of each other and a common language, expressed that their team spirit was poor. These difficulties put pressure on the entire team, along with poor performance and the resulting loss of 11 games as the fall season came to a close.

The head coach felt challenged in rebuilding the team and recovering positive spirit among the players, and searched for team building ideas, taking up the idea of the musical intervention. During discussions, he saw resemblance between team coordination in music and in ice hockey chains. The intervention, designed for business organizations, also fit the sports context because this team situation, involving international collaboration, rapid change, and group coordination, drew many parallels with contemporary business settings. He pointed out that the team already used music during training and games to motivate team members and animate the community, making the use of music for team development seem intuitive.

After consultation around the goals of emotional engagement and team development, the consultant designed and introduced the intervention plan, similar in nature to interventions carried out in non-sports business contexts. The intervention 
was based on a creative change method called $\operatorname{ReDoMe}{ }^{\circledR}{ }^{1}$, and consisted of defining the goals and resources at hand, designing and executing musical interventions, and evaluating and reflecting upon the results.

\subsection{Data Collection and Analysis}

Based on the second author's involvement in the project, we had the opportunity to gather data in situ for the purpose of the study, consisting of interviews and observations during the program. We also accessed publicly available data in the form of video-recorded interviews from the team's website, occurring before and after games. These videos were used by consultants during the invention, as an information source about the team's dynamics when they were planning the intervention. We watched these videos and looked for both verbal and gestural information (e.g. Fele, 2012) about how players and coaches addressed issues related to losing the games, focusing on communication around how they understood and attempted to articulate their team difficulties.

Video recordings of the actual intervention, in which the players rehearsed, used instruments, and performed, were also collected. The intervention videos allowed us to systematically follow individual and collective practices during the 2hour intervention. We focused specifically on the embodied communication (Cunliffe \& Coupland, 2012), paying close attention to how players used their bodies, gestures, and gaze during the intervention. As Taylor (2002) points out, respondents often have difficulty talking about their 'felt sense', reflecting aesthetic muteness in data collection within artistic interventions. Video research is uniquely poised to study difficult-to-articulate aesthetic knowledge (Toraldo et al., 2016), making it

\footnotetext{
1 The intervention focused on management and team development in a rock band context, and an online networking tool was used to collect reflective information and ideas during the intervention.
} 
appropriate in the current context. Focusing on communication, gesture, tool uses, and players' 'felt sense', we attempted to get close to how participants displayed their experiences in the situation. Our third data source was the video recorded interview with the coach and online interviews with the players after the intervention, allowing us to explore the subjective experiences of participants and the ways that they made sense of and communicated these experiences.

Table 1 About Here

As an analytical strategy, we adopted an iterative approach, based on emerging theory and data analysis (e.g. Charmaz, 2006; Corbin \& Strauss, 2008). Beginning with the broad interest around the aesthetic and communicative bases of artistic interventions, which grounded our research question and served as "sensitizing concepts" (Blumer, 1954). For further analysis, we began by exploring the sources of the organizational coordination problem as discussed in the interviews with the players and coach. Our initial phase of coding focused on how they described their situation and difficulties, leading us to focus more specifically on a dilemma around articulating their diverse experiences. Within this category, we noted team members' difficulties in expressing their tacit knowledge, linked to emotional difficulties, and the frustrations of difficult-to-articulate knowledge. We further noted team coordination difficulties that players were aware of but had not explicitly articulated, and socially sensitive concerns around their work, such as violence in play and other frustrations (Table 2).

From these initial difficulties, we examined the musical intervention process to explore how it approached gaps in articulating coordination processes, coding data by identifying practitioners, activities, and key events around which articulation was facilitated. The data was coded together, in order to triangulate between different data 
sources and to help confirm emerging codes. Nevertheless, the multimodality of the different data sources allowed unique aspects of the intervention process to become apparent (cf. LeBaron, Jarzabkowski, Pratt \& Fetzer, in press). For example, the video data was particularly revealing of the roles of object use and material interactions, while the interviews with coaches and players highlighted the sensemaking processes by which members understood their experiences of the intervention. Table 2 provides a summary of the data coding process.

Table 2 About Here

In our results, we begin with an overview of the activities associated with designing and implementing the intervention, followed by the key themes of articulating team challenges and coordinating via sociomaterial processes.

\subsection{Designing and Implementing the Intervention}

The design of the intervention involved conversations with the head coach and players, a team of four musical coaches, a senior consultant, and a psychologist. The consultancy team studied the team's "musical transcription" in its engagement with and communication between the team, fans, and audience during the games.

The "musical transcription" involved a list of songs played during games for energy and concentration, and after the games for celebration, relaxation and quick recovery. Songs marked strategic moments in the game, and had the spectacular effect of a live stage performance. For example, opening songs were played when the team enters the ice hockey rink, for the entry of the visiting team, at goal scoring moments, penalties, breaks in-between periods, and game victory. Other songs were used by the fan base for cheering during the breaks. 
The musical intervention was introduced during the final practice of the season, just before the season ended, and involved 2-hour coaching session where the team was rebuilt as a rock band. Three workshops were conducted, for learning guitar and keyboards, practicing rhythm, and lyrics, respectively. In each workshop, players were given tasks around playing the winning song and performing to team supporters. Learning to play an instrument was a new experience to most of the players.

To support individual engagement, the players were guided to make active connections with the instruments and with each other. The coaches gave feedback and supported the participation and exploration. The players were told to listen to each other and synchronize their rhythms. The focus was initially on the instruments, music and playing. Gradually, participants were instructed to move their focus from individual performance to team collaboration. When taking turns to rehearse instruments, the players were instructed to teach each other to play what they had just learned. The process allowed players and the management to identify moments where support and encouragement were needed. After going through all the workshops, the players collectively gathered into a single musical group to perform together. To maximize the "good spirit" and positive feedback, a well-known rap musician joined the final practice before going on stage. The intervention finished in a party performance with the whole organization including supporting staff and fans.

During the intervention, according to the head coach, "The level of activity and energy was very high the whole time and it was interesting to see how each player found their position in the band one after another." He emphasized the importance of "creat[ing] experiences of good cooperation, also outside of ice hockey". The collaboration with the consultant and the head coach continued for 
final interviews and input after a month from the intervention. The team had made a comeback, and finished the spring season with a winning record.

During these interventions, issues of difficulties in articulating affectively intense experiences, and working together through instruments, were faced by participants, as confirmed in observations and interviews. We now turn to these difficulties and coordination processes.

\section{Findings}

\subsection{Difficulties in Articulation}

The initial phases of contact focused on communicating personal anxieties and group frustrations. As noted above, the embodied experience of difficult collective coordination were not easily accessible in words. As the season's losses accumulated, team insecurities increased, but members expressed hesitation in bringing these up publicly. One player noted that 'it's fairly hard to assess one's own performance when there are these losses". These articulation difficulties involved emotional anxieties around performance, struggles to represent tacit knowledge, and difficulties explaining irrational behavior during play.

\subsubsection{Discussing Emotions around Performance}

Fear of losing was cited as a key emotional challenge facing the team, and was the central theme occupying the team at the time of contact. The following interview excerpt illustrates the players' attempts to understand a fifth serial loss:

Interviewer: Phew, what a game. It looked like we were doing fine but then the opponent shot the goals.

Player 1: It's been difficult for us lately. Although we are still in the game and sometimes even ahead, we are not scoring. And when there are these losses, it is not much helping us."

The players expressed difficulty articulating their reactions to losing; in the above example, the player suggests a vicious circle where losses make it difficult to score 
goals, but struggled to explain why the losses had such an effect. In general, the players hesitated to express negative emotions, acknowledging their difficult situation but not describing their own intimate feelings or sharing these with teammates. As one player put it, "we have not given up, we just need to work hard". Making the situation more difficult, several players seemed emotionally disconnected from the team and expressed dissatisfaction with other members. The taboo around expressing fear, particularly within the masculinized atmosphere of professional hockey, led to avoidance and denial. As the head coach described, the team was suffering from a "mental lock" affecting performance.

\subsubsection{Putting Tacit Knowledge into Words}

Another factor limiting discourse around loss was that the players felt that the secrets of winning in ice-hockey were elusive and tacit, embodied in know-how that should be second nature for the players:

"Sports journalist: What do you think, are the problems more related to the game or the spirit?

Player 2: Well, we do know the game, we just need to keep the home base clean."

Metaphorical uses like "cleaning the home base" condensed complex knowledge in ways that were familiar to the team, yet were difficult to unpack in terms of specific practices and interactions, making coordination difficult. The player asserts that they "know the game", such knowledge being part of the professional role, but digging further than the presupposition of knowledge was difficult in discussions. Players struggled to explain in rational terms the reasons for losing or the steps they should take to win. Absent from discussion was the emotional dynamic of the team (i.e. "the spirit"), which was compromising "the game" itself; the ill-defined sense that something was wrong at "the home base" produced a vague acknowledgement that the team needed a way to recreate its unity; but how? 


\subsubsection{Taboo Behaviour on the Ice}

"Sports journalist: How would you explain the situation?

The coach: One of the problems is the power plays. The situation is now 11 to 4 [the scores done during power play]. We have to be able to be able to get at least even."

During games, the news media pointed out several times the increasingly violent play of the team, and the accompanying increase of misconduct penalties. Violence toward opponents in ice-hockey is common, but is circumscribed by norms about how and when it can be expressed; a sudden increase of violence can be interpreted as a reaction to frustration around loss of control and team disintegration. The coach and team members acknowledged that the increase in violence was not a functional or strategic choice, but an irrational outburst that was difficult to control.

"Even a soft tap on a hockey stick and the opponent scores during their power play. We need to learn to control these." (Coach)

In ice-hockey, this irrationality evidenced when violence results in penalties that give advantage to the opponent. Such behavior was reinforcing the vicious cycle and the teams" "negative whirlpool".

Beyond violent behavior per se, another taboo among team members involved the tension between individual benefit and playing for the team. Problems in cohesion and trust among team members led to individual attempts to compensate "on their own", reducing teamwork. Players recognized this strategy as contributing to their losing streak:

Interviewer (sport's journalist): It's now 4 losses in a row. How will the team sort this out before the next game?

Player 2: We need to unite more strongly. You shouldn't have only your own scores in your mind but we should play for the team.

Playing for one's own benefit or for the team's benefit relates to coopetition (Lundgren-Henriksson \& Kock, 2016), and requires coping with emotions that the individual-group tension creates. As players are assessed based on both individual 
scores and team performance, there was the constant temptation to focus energy away from actions that contribute to the collective. At the same time, the expectation for a team effort made such individualism a taboo topic among members.

In short, various tensions around teamwork and performance, difficult to articulate for multiple reasons, characterized a downward spiral in the team. These issues - fear of loss, tacit know-how, aggressiveness and individualism - were situated within the hockey context but are classical tensions across teams in business contexts as well.

\subsection{Socio-material objects in musical interventions}

The musical interventions began by working through experiences of the players using musical instruments, considered as socio-material objects supporting new forms of practice. The intervention was organized so that each player could play different instruments and experience different roles in the band. As a reaction to the instruments, the coach noted, "There is always some kind of an instrument for everyone to play with. And the feeling when you succeed [to get the sound out of it], it just makes you feel good [smiles, with laughter]." The players experimented with guitar and keyboards, then drums and percussions, and finally lyrics and vocals. The consultants used a simple notation depicting musical information in colors and symbols and players received instruction on holding and playing the instrument. The song was the team's victory theme; thus, the lyrics and vocals were already familiar.

The intervention began with a sense of awkwardness as players were initially reticent and somewhat stiff, their nervousness visible in body language. Some players faced the wall, turning away from the ongoing activity, while others attended more eagerly, leaning towards the song sheet, holding and touching the instruments, and 
maintaining eye contact with each other and the consultants. As expressed in the interviews,

"In our team we had players that first were standing a bit further away and wondering whether they have courage to come along. But then when I saw the performance, they were sitting next to the keyboard and looking at the sheet tightly, and it was obvious that they enjoyed it."

As interaction with the instruments began, however, active involvement increased and became the norm throughout the intervention. The embodied experience of holding and playing the instruments during the intervention provided a means of expressing tacit experience and emotions, via material artefacts, in ways that were communicable and social. As the musical instruments possess, by virtue of their materiality, action possibilities for holding, fiddling, experimenting or just producing noise, this enabled the players to convey their experiences of the situation without having to give verbal descriptions.

The structuring yet pliable nature of the material artefacts and the challenging but ultimately achievable interactions with the instruments were key to alleviating the fear of failure that was endemic to the team. As one player describes it,

"There is nothing to lose in this intervention. It's something that is for sure."

The ability to form a stable relation to an objective artefact, through which interactions with others were facilitated, addressed the ongoing anxieties of the team regarding their ability for effective action.

Overall, there was hardly any conversation during the sessions, a fact appreciated by both the players and managers. The musical intervention thus created a space for embodied communication by bringing the instruments into the situation and enabling the participants to take some distance from their verbal communication by forming a human-instrument relation. Grounding their interaction in sensory, aesthetic 
and material practices, the instruments used in the musical intervention allowed the player to non-verbally demonstrate emotions such as insecurity, lack of involvement, or fear that may have otherwise been taboo or sensitive.

Furthermore, the fact that each instrument carries a specific function within a band, structuring how players can participate, evokes the notion of 'ventriloquism' (Cooren, 2010). According to Cooren (2010: 90) ventriloquism takes place when "semiotic beings, whether we like it or not, make us to do things ... as much as we make them to do things". When the players were asked to choose their favorite instrument for the performance, the material relations to these instruments structured their relationships, evoking relationships familiar to them in the team. For instance, the strikers chose to be the lead vocalists or play the guitar, the goal keeper chose to play drums, and the defenders played the key boards and bass guitar. This division of labor was explicitly recognized by the members and the coach:

"There are different roles in a band as is the case also in ice hockey teams. Someone is a soloist and some play the beat and these roles often emerge quite naturally. In the intervention I was surprised how quickly the roles from the team were played out in the band."(Head coach)

Although the intervention was designed so as to enable the players to explore different roles in a new context, instruments and the rock band setting created an opportunity to establish an "embodied metaphor" from the ice-hockey rink (Heracleous \& Jacobs, 2008). In other words, the players established through the musical intervention aesthetically grounded patterns and shapes that meaningfully structured their perceptions, images, and events across settings (cf. Lakoff \& Johnson, 1999). The opportunity to alternate instruments and roles in a rock band leveraged the metaphor to establish spaces for experimentation difficult to achieve in the hockey team itself. This flexibility allowed players to recognize and explore from a distance the power factors and tensions between the players. 
Based on the above, the material interactions and aesthetic experience of the intervention both structured the player's experiences, giving them material and metaphorical supports for understanding their team interaction, while loosening the hold of encrusted patterns of team dysfunction, by enabling new expressive opportunities and role experimentation. The aesthetic nature of their activity allowed expression where articulation in words was difficult. Below we explain how the intervention supported team communication by linking the material interactions to social coordination processes.

\subsection{Synchronizing team members}

While the musical intervention highlighted aesthetics and material interactions to support players' articulation of their experiences, frustrations and anxieties, it also aimed to move beyond individual experience by synchronizing group members around a common material-aesthetic project. To move from individual experience to group communication, collectively available objects and collectively synchronized practices were central to the intervention. One method, body-percussion, had particular resonance as a communicative support. The team was given a simple rhythmic training, during which the importance of keeping the pace was emphasized; players throughout the exercise adjusted their speeds in the attempt to maintain synchronicity. They were instructed simultaneously to focus on bodily synchronization, moving their right hand and left foot so that the group would create a common rhythm. Next, the players were trained to recognize a given volume and balance by playing too fast, too slow, too loud, and too quietly. During the rehearsal, the players were able, after some experimentation, to play together body-percussions in the same beat and maintain a synchronized rhythm. As described by one of the captains of the team: 
"It was enjoyable to see that we can play together, this improved team spirit." (Team captain)

Similar to above discussed notions of "acting in concert" (Mattern, 1998) and “communitas" (Turner, 1974), these synchronizing activities were geared toward building the sense of the group as a whole and aligning individual practices to a larger project. The group rhythm could be adapted by modulating individual actions, but such possibilities were not individually idiosyncratic but had to "fit" within the current rhythmic possibilities. They were thus able to directly follow the impact that they had on the group, while being held by the group dynamic. Body-percussion helped to shift the players' focus from individual to social by structuring their aesthetic experience as an interdependent achievement.

At the first successful experiments during the body-percussion session, the players burst into laughter and spontaneous applause. Positive feedback from the consultants led them to relax and observe other group members as they aligned their beats. One of the players described the activities in the following way:

"Before the rehearsal we were rather skeptical but quickly we lost ourselves in the rehearsal." (Player)

This turn from skepticism to commitment was reiterated by the head coach. For him, the turning point came as one of the players joined the band later in the process, just before the performance. Previously, he had been observing the workshop from a distance, but would not enter or practice with the others. Yet, during the final practice, as the team rehearsed before going on stage, the player approached the consultant and asked to participate saying "show me quickly" and stood behind the keyboard. This act, as explained later by the coach, made an important symbolic difference and coalesced the team while dispersing previous doubts. The collective nature of the intervention was reinforced, as the coach put it: 
"It felt great also for me. I think this intervention doesn't leave anyone out in the cold. Everyone will throw themselves into this eventually." (Head coach)

After the three workshops, the atmosphere became increasingly relaxed and the playing had volume and intensity. The players smiled and had eye contact with each other while remaining focused and present in the moment. Players' bodies begun to move in synch and the group seemed to follow a precise rhythm. As one of the captains put it after the rehearsal:

"When we do enjoyable things in a large group, it knits us together" (Team captain)

Beyond their group performance, a central aspect bringing the collective together during the intervention was the joining of the rap-musician to the training. The presence of the outside artist, one known to and respected by the players, increased the intensity of the intervention and lifted players' energy. During their rehearsals together, they danced and moved freely, clapping hands and singing along in the chorus.

"Oooh, this city is mine, I own this place entirely.

Oooh, there no other like this, here I am at home."

At the end of the intervention, an event was organized for the team's fans and supporting staff. In the performance, the team positioned themselves spontaneously in a tight group formation. Many players reported being nervous and excited to perform on a live stage after a short period of training. Despite the initial nervousness, however, after the experience, the players described feeling energized and cohesive. As one of the players put it: "It was fun and uniting experience!" Similar statements of the experience as "Such a neat experience!" or "Everyone liked it" created the impression that the members had come to a shared appreciation that was "uniting". They reported that recognizing their ability to play music together was empowering, and one player noted that, rather than just "strumming on" as backup, the 
empowerment came from active involvement in the music. Figure 1 provides a portrait of the team during the musical intervention.

Figure 1 About Here

\section{Discussion}

The current study, by examining the use of music in collaborative teamwork through an artistic intervention, explores the mutual influence of aesthetic experience and organizational communication in team coordination processes. Problems in team coordination arose from the affective, cognitive, and social difficulties in articulating elusive knowledge, and music provided an experimental and collaborative medium to work out these difficulties in practice. Material artefacts grounded experience in publicly available forms to analogize team processes and mediate emotionally sensitive coordination. At the same time, synchronization processes necessary for musical coordination structured the movement from individual to collective experience, and gave the sense of a collectively produced result that bound team members together. While we do not claim that such processes were singularly responsible for the team's subsequent performance, team members and coaches considered the intervention as a watershed moment in which the team was able to kick-start its collaboration and reengage in joint action. The musical intervention helped to "vent" negative emotions and to create a more fluent, generative dialogue that empowered those members who had difficulties in putting the 'problem' into words. "A little less conversation, a little more action" tries to capture the insight that when problems are difficult to put in words, acting together can complement the more rational-analytic processes of verbalization. In our case, the musical intervention helped to manage emotions and energy within the organizational context (Schiuma, 2011). 
From the perspective of bridging individual experience and collective communication, the musical intervention simultaneously worked at both levels of analysis, which was possible for several reasons. First, the stress-relieving and expressive experiences of the music facilitated otherwise tense interpersonal interactions. As the head coach noted during discussion, "It's typical for Finnish players to moan over mistakes for a long time". Attributing this to culture, the coach contrasted Finnish and Czech hockey cultures, saying that Finnish hockey does not allow self-forgiveness, and the negative energy that results can lead players to distance themselves from the team and lose their sense of belonging.

In this context, the re-discovery of the collective was met with fear but also eagerness. For example, as one team member expressed how anxiety gave way to relief, "it was very scary in the beginning but soon turned out to be easy and enjoyable". The emotion-related aspects of improving mood created an open climate where the players listened to each other, were able to change perspective, and created a generative dialogue. As they became aware that they enjoyed playing music together, they reinforced social bonds and began to see themselves, their organization, and their fan base in the city as part of a community.

In sum, the material-aesthetic aspect of the intervention, in which individuals worked on difficult-to-articulate experiences, fed into and supported the collective coordination process, which involved the synching of team members through coordinated activity. Figure 2 provides a visual representation of these insights.

Figure 2 About Here

As Figure 2 depicts, the difficulty in articulating experiences and coordinating collectively is worked through aesthetic material processes at the individual level, 
through the human-instrument relation (illustrated by the reciprocal arrows in the individuals' ovals), and collectively, through the synching processes (illustrated by the embracing oval), with individual level material and collective processes also related to each other. The ultimate goal was to provide an individual and collective resource to rebuild the mutual embodied relations of the players through the aesthetic supports.

\subsection{Theoretical and practical implications}

The current study contributes to understanding the aesthetic bases of arts-based interventions (e.g. Barry \& Meisiek, 2010; de Monthoux \& Statler, 2008; Meisiek \& Barry, 2014) by empirically examining how artistic knowledge, through its focus on aesthetic forms of knowing, can ground team coordination efforts. We propose that the aesthetic, material, and interpersonal aspects are entangled in a process we refer to as embodied communication, a concept that helps to explain arts-based interventions' ability to promote new forms of experience and organizing (Taylor \& Ladkin, 2009). Research on arts-based ways of knowing (e.g. Barry \& Meisiek, 2010; Schiuma, 2011; Taylor \& Hansen, 2005) has emphasized how unique ways of seeing and knowing via the arts can inform organizational practice; organizational members can benefit from aesthetic understandings of organization (Strati, 2010) that are associated with organizational learning (Berthoin Antal, 2013). While much aesthetic literature focuses on individual experience and judgment, aesthetic processes are fundamentally collective and communicative. Further, recent literature suggests that arts-based approaches work though promoting the expression of thoughts and feelings normally not expressed in everyday organizational life (Berthoin Antal et al, 2014). However, we contribute to this literature by showing that the unique relationship between aesthetic knowledge and team communication emerges in a process in which inarticulable knowledge is materially mediated through aesthetic experience (music), 
providing a platform for opaque or elusive knowledge to be communicated (Endrissat et al., 2016; Toraldo et al, 2016).

Elaborating on this contribution, the ability for aesthetic understanding to ground team communication involves a two-way relationship between aesthetics and communication that is not fully theorized in either literature. The aesthetics literature acknowledges the collective nature of aesthetic understandings (e.g. Ewenstein \& Whyte, 2007), yet the tendency of aesthetics to focus immediate sensory knowledge (e.g. Palmer, Schloss \& Sammartino, 2013) means that individual experience is often privileged over interactional processes. On the other hand, while the CCO literature acknowledges the materiality of texts and discourses as communicative artefacts (e.g. Ashcraft et al, 2009; Sorsa et al. 2014), it emphasizes the discursive and textual over the material artefacts that support communicative processes. In short, the ability of the aesthetic to express experiences beyond words complements our knowledge about materiality and the communicative constitution of organization. Extending Cooren's (2015) work on semantic materiality, we make the case for music and how aesthetic materiality provides a platform for the inarticulate to be communicated, extending the understanding of aesthetics as a collective and a communicative process.

In terms of applied contributions, by examining musical interventions we explore a less-studied phenomenon within the broader field of artistic interventions. While interventions have been discussed in terms of organizational theatre, for example (Clark \& Mangham, 2004), and in terms of visual artistic interventions (e.g. Berthoin Antal et al., 2014), musical interventions remain to be explored in empirical research, although the importance of music as a form of art-based initiative has been noted (Schiuma, 2011). Our study, although situated in a sports context, informs 
artistic intervention research more generally, by linking musical interventions with team processes and the use of material artefacts in sustaining collective coordination.

\subsection{Directions for Future Research}

Given the rapidly increasing interest in arts-based interventions (Meisiek \& Barry, 2014; Schiuma, 2011), the current study diversifies current empirical work to new settings while contributing to the theoretical base of the literature. First, we focused on a single sports organization and a specific art-form, collective music making, but our contribution is applicable to arts-based interventions more generally. Some aspects of team sports may invite analogies with musical bands; the emphasis on close coordination, for example, as well as the importance of exact timing of collective virtuosity (Marotto et al, 2007). However, the more general point about aesthetic supports for communication processes is specific neither to musical groups nor sportsbased teams; thus, our conceptual contribution should apply more broadly, and invites future research to study interventions involving a variety of artistic intervention forms and diverse organizational contexts.

Similarly, within the sub-field of musical interventions, further explorations could look at the role of different instruments, genres, and forms of musical organization in experimenting with collective processes. For instance, a relatively leaderless and informal process like that within a rock band could produce distinct effects than that of a tightly controlled quartet or acapella group, the centralized direction of an orchestra, or the call-response framework of a jazz improvisation, for example. Once the analogy between musical and team coordination has been established, a variety of different parameters of coordination are opened up, creating a field for both empirical research and applied initiatives. 
In addition, while our study focused on the team level, our theoretical approach is appropriate for any level of analysis in which difficult-to-articulate knowledge requires communication across boundaries, whether interpersonal or organizational. For instance, the collaboration between the sportsmen, musicians, and the rap artists could be understood as an inter-organizational collaboration, although this aspect was not the objective of the interventions. Future research might examine how arts-based initiative can coordinate inter-organizational contacts, for example, in the context of alliances, mergers and acquisitions, or inter-firm negotiations.

Finally, while our case stresses empowerment and the emancipatory potential of musical interventions (Small, 1998) to support the team in regaining their performance strength, musical interventions, and its aesthetic material base in particular, might also be used as an instrument of managerial control. Calling attention to the material base of aesthetic enchantment (Hancock, 2005), we invite future studies to pay more attention to power struggles in artistic interventions.

\section{Conclusion}

In sum, within the emerging field of arts-based interventions, music offers a rich yet understudied opportunity to explore the interface of people and instruments and to understand how the latter can serve as objects of coordination whereby team members elaborate and articulate elusive knowledge about their team's functioning. Processes of synchronization and collective participation inherent in musical performance act as scaffolds around which participants can create new understandings of themselves and their colleagues, and work though difficulties that could not find expression in words. As a junction of the aesthetic, the material medium, and the interpersonal dynamic, music provides a collective mechanism by which groups can find their collective rhythm and explore new ways to synchronize their efforts. 


\section{References}

Adler, N.J. \& Ippolito, L.M. (2016). Musical leadership and societal transformation: inspiration and courage in action. Learning Landscapes, 9(2), 23-47.

Ashcraft, K., Kuhn, T. \& Cooren, F. (2009). Constitutional amendments: "Materializing" organizational communication. The Academy of Management Annals, 3(1), 1-64.

Barry, D., \& Meisiek, S. (2010). Seeing more and seeing differently: Sensemaking, mindfulness, and the workarts. Organization Studies, 31(11), 1505-1530.

Berthoin Antal,A. (2013). When arts enter organizational spaces: implications for organizational learning', in P. Meusburger, A. Berthoin Antal and L. Suarsana (eds.) Learning Organizations: Extending the Field (pp. 177-201). Dordrecht: Springer.

Berthoin Antal,A., Taylor, S.S., \& Ladkin, D. (2014). Arts-based interventions and organizational development: It's what you don't see. In Bell, E., Warren, S., \& Schroeder, J. (Eds.), The Routledge Companion to Visual Organization (pp. 261-272). London: Routledge.

Berthoin Antal, A., \& Strauß, A. (2014). Not only art's task-Narrating bridges between unusual experiences with art and organizational identity. Scandinavian Journal of Management, 30(1), 114-123.

Blumer, H. (1954). What is wrong with social theory? American Sociological Review, 18, 3-10.

Blunt, L. (1994). Music therapy. An Art Beyond words. Routledge, London.

Charmaz, K. (2006). Constructing grounded theory: A practical guide through qualitative analysis. London: SAGE Publications.

Clark, T. \& Mangham, I. (2004). Stripping to the undercoat: a review and reflections on a piece of organization theatre, Organization Studies 25(5), 841-851.

Corbin, J., \& Strauss, A. (2008). Basics of qualitative research: Techniques to developing grounded theory ( $3^{\text {rd }}$ Ed.). Los Angeles, CA: Sage.

Cooren, F. (2006) The organizational communication-discourse tilt : A refugee's perspective. Management Communication Quarterly, 19: 653-660.

Cooren, F. (2010) Action and agency in dialogue. Philadelphia, PA: John Benjamins.

Cooren, F. (2015). In medias res: communication, existence, and materiality. Communication research and practice, DOI: 10.1080/22041451.2015.1110075

Cooren, F., Kuhn, T., Cornelissen, J.P. \& Clark, T. (2011). Communication, organizing and organization: An overview and introduction to the special issue. Organization Studies, 32(9), 1149-1170. 
Cooren, F., Vaara, E., Langley, A., \& Tsoukas, H. (2014). Language and communication at work: Discourse, narrativity, and organizing. Oxford: Oxford university Press.

Cunliffe, A., Coupland, C. (2012) From hero to villain to hero: Making experience sensible through embodied narrative sensemaking. Human Relations, 65, 63-88.

El-Sawad, A., \& Korczynski, M. (2007). Management and music: The exceptional case of the IBM songbook. Group \& Organization Management, 32(1), 79-108.

Endrissat, N., Islam, G. \& Noppeney, C. (2016) Visual organizing: Balancing coordination and creative freedom via mood boards. Journal of Business Research, 69, 2363-2362.

Ewenstein, B., Whyte J. (2007). Beyond words: Aesthetic knowledge and knowing in organizations. Organization Studies, 28(5), 689-708.

Fele, G. (2012). The use of video to document tacit participation in an emergency operations centre. Qualitative Research, 12(3), 280-303.

Flyvbjerg, B. (2006). Five misunderstandings about case-study research. Qualitative Inquiry, 12(2), 219-245.

Furu, P. (2012). The art of collaborative leadership in jazz bands. In J.Caust (ed.), Arts leadership international case studies. Tilde:Tilde university press.

Gagliardi, P. (1996). Exploring the aesthetic side of organizational life, In: S. Clegg, C.Hardy, \& W. Nord, Handbook of organizational studies, London: Sage.

Hancock, P. (2005). Uncovering the semiotic in organizational aesthetics. Organization, 12(1), 29-50.

Hardy, C. (2004). Scaling up and bearing down in discourse analysis: questions regarding textual agencies and their context. Organization, 11, 415-25.

Heracleous, L. \& Jacobs, C. (2008). Crafting strategy: The role of embodied metaphors. Long Range Planning, 41, 309-325.

Jones, S., \& Schumacher, T. (1992). Muzak: On functional music and power. Critical Studies in Mass Communication, 9(2), 156-169.

Koelsch, S., Kasper, E., Sammler, D., Schulze, K., Gunter, T. \& Friederici, A. (2004) Music, language and meaning: brain signatures of semantic processing. Nature Neuroscience, 7(3), 96.

Korczynski, M. (2003). Music at work: Towards a historical overview. Folk Music Journal, 8, 314-334.

Korczynski, M., Robertson, E., Pickering, M., \& Jones, K. (2005). "We sang ourselves through that war": Women, music and factory work in World War 
Two. Labour History Review, 70, 187-214.

Korczynski, M., Pickering, M., \& Robertson, E.(2008). The last British work songs: Music, community and class in the Kent hop fields of the early-mid 20th century. Management \& Organizational History, 3(1), 81-102

Lakoff, G., Johnson, M.(1999) Philosophy in the flesh: the embodied mind and its challenge to western thought. New York: Basic Books.

LeBaron, C., Jarzabkowski, P., Pratt,M., and Fetzer, G.(in press). Video-based methods in organizational studies. Organizational Research Methods.

Lundgren-Henriksson, E. \& Kock, S. (2016). A sensemaking perspective on coopetition. Industrial Marketing Management, 57, 97-108.

Marotto, M., Roos, J., \& Victor, B. (2007). Collective virtuosity in organizations: A study of peak performance in an orchestra. Journal of Management Studies, 44(3), 388-413.

Martin, P.Y. (2002). Sensations, Bodies, and the "Spirit of a Place": Aesthetics in Residential Organizations for the Elderly. Human Relations, 55(7), 861-885.

Mattern, M. (1998). Acting in concert: Music, community, and political action. New Brunswick, NJ: Rutgers. University Press.

Meisiek, S. \& Barry, D. (2014). The science of making management an art. Scandinavian Journal of Management, 30(1), 134-141.

Meisiek, S. \& Hatch, M.J. (2008). This is work, this is play: Artful interventions and identity dynamics. The SAGE handbook of new approaches in management and organization, 412-422.

Monthoux, P.G.D., \& Statler, M. (2008). Aesthetic play as an organizing principle. The SAGE handbook of new approaches in management and organization, 423.

Nicolini, D. (2012). Practice Theory. Work, and Organization. Oxford: OUP.

Nissley, N. (2002). Tuning to Organizational Song as Aesthetic Discourse. Culture and Organization, 8(1), 51-68.

Palmer, S.E., Schloss, K.B., \& Sammartino, J. (2013). Visual aesthetics and human preference. Annual Review of Psychology, 64, 77-107.

Peretz, I. \& Zatorre, R.Q. (2005). Brain Organization for Music Processing. Annual Review of Psychology, 56, 89-114.

Prichard, C., Korczynski, M., \& Elmes, M. (2007). Music at work: An introduction. Group \& Organization Management, 32(1), 4-21. 
Putnam, L. \& Nicotera, A.(Eds. 2009). Building theories of organization: The constitutive role of communication. New York: Routledge.

Schiuma, G. (2011). The value of arts for business. Cambridge: University Press.

Small, C. (1998). Musicking. The meanings of performing and listening. Middletown, CT: Wesleyan University Press.

Sorsa, V., Pälli, P., \& Mikkola, P.(2014) Appropriating the words of strategy in performance appraisal interviews. Management Communication Quarterly, 28(1), 56-83.

Strati, A.(1992). Aesthetic understanding of organizational life. Academy of Management Review, 17(3), 568-581.

Strati, A.(2010). Aesthetic understanding of work and organizational life: approaches and research developments. Sociology Compass 4(10): 880 - 893.

Strati, A., \& de Montoux, P.G. (2002). Introduction: Organizing aesthetics. Human Relations, 55, 755-766.

Styhre, A. (2008). Perception and Organization: Art, Music, Media. Basingstoke: Palgrave Macmillan.

Taylor, S.S. (2002). Overcoming aesthetic muteness: Researching organizational members' aesthetic experience. Human Relations, 55(7), 821-840.

Taylor, S.S. \& Hansen, H. (2005). Finding form: Looking at the field of organizational aesthetics. Journal of Management Studies, 42(6), 1211-1231.

Taylor, J. (2014). Impersonating the organization: Reflections on the communicative constitution of organization. In Cooren, F., Vaara, E., Langley, A., \& Tsoukas, H. (Eds.) Language and communication at work: Discourse, narrativity, and organizing, pp. 17-38. Oxford: Oxford University Press.

Taylor, S.S., \& Ladkin, D. (2009). Understanding arts-based methods in managerial development. Academy of Management Learning \& Education, 8(1), 55-69.

Toraldo, M.L., Islam, G. \& Mangia. G. (2016). Modes of knowing: Video research, multimodality and the problem of elusive knowledges. Organizational Research Methods, published online, doi: 10.1177/1094428116657394

Turner, V. (1974). Dramas, fields, and metaphors: Symbolic action in human society. New York: Cornell University Press.

Warren, S. (2008). Empirical challenges in organizational aesthetics research:

Towards a sensual methodology, Organization Studies, 29(4), 559-580. 
Table 1. Collected Data Types

\begin{tabular}{|c|c|c|c|c|c|c|}
\hline \multirow[b]{2}{*}{ Data Source } & \multicolumn{2}{|c|}{$\begin{array}{l}\text { Before the musical } \\
\text { intervention }\end{array}$} & \multirow{2}{*}{$\begin{array}{l}\text { Musical intervention } \\
\text { Video of intervention } \\
\text { (2.5 hours) }\end{array}$} & \multicolumn{3}{|c|}{$\begin{array}{c}\text { After the musical } \\
\text { intervention }\end{array}$} \\
\hline & $\begin{array}{l}\text { Observa- } \\
\text { tions }\end{array}$ & $\begin{array}{c}\text { Video- } \\
\text { interview } \\
\mathrm{s} *\end{array}$ & & $\begin{array}{l}\text { Observa- } \\
\text { tions }\end{array}$ & $\begin{array}{l}\text { Online } \\
\text { survey } \\
\text { (leading } \\
\text { players) }\end{array}$ & $\begin{array}{l}\text { Video- } \\
\text { interview } \\
\mathrm{s} *\end{array}$ \\
\hline Players (15) & & $\mathrm{x}$ & $\mathrm{x}$ & & $\mathrm{x}$ & \\
\hline Head coach & $\mathrm{x}$ & $\mathrm{x}$ & & $\mathrm{x}$ & & $\mathrm{x}$ \\
\hline Artist & $\mathrm{x}$ & & $\mathrm{x}$ & & & \\
\hline Psychologist & $\mathrm{x}$ & & & $\mathrm{x}$ & & \\
\hline Consultant & $\mathrm{x}$ & & $\mathrm{x}$ & $\mathrm{x}$ & & \\
\hline $\begin{array}{l}\text { Musical coaches } \\
\text { (4) }\end{array}$ & & & $\mathrm{x}$ & $\mathrm{x}$ & & \\
\hline
\end{tabular}

* publically available data 


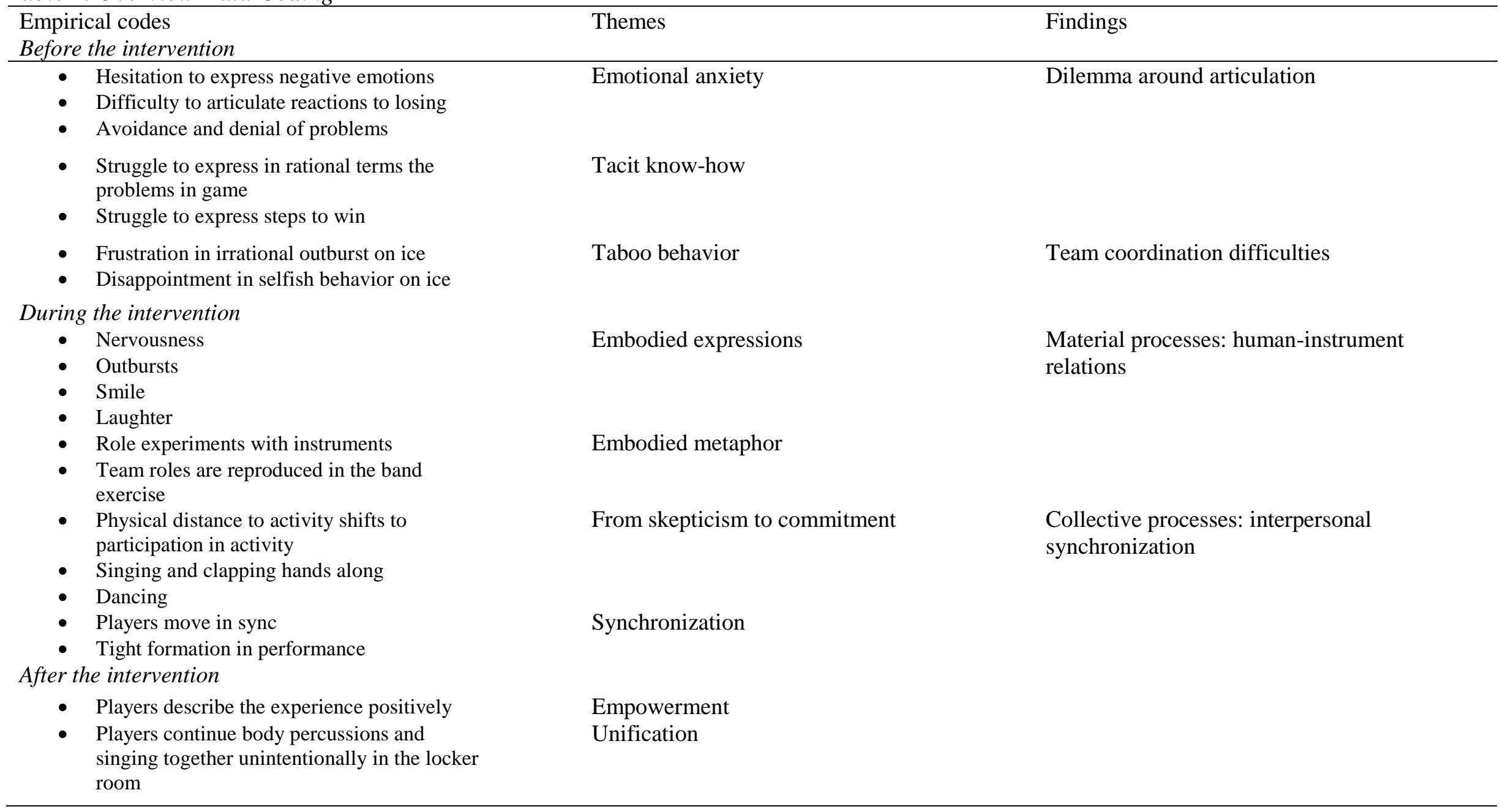


Figure 1. Picture of Hockey Team during Musical Intervention

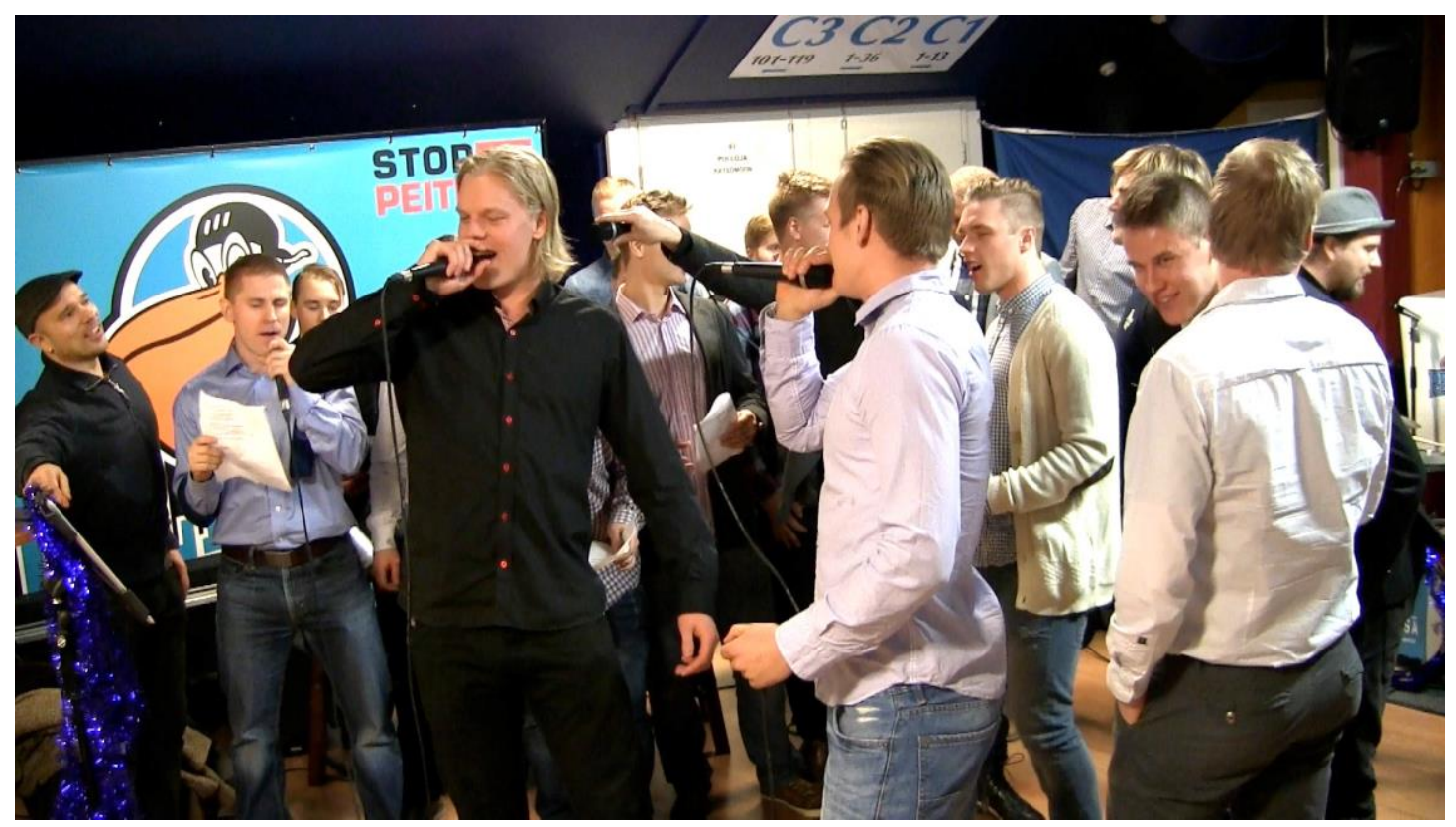


Figure 2. Conceptual Framework

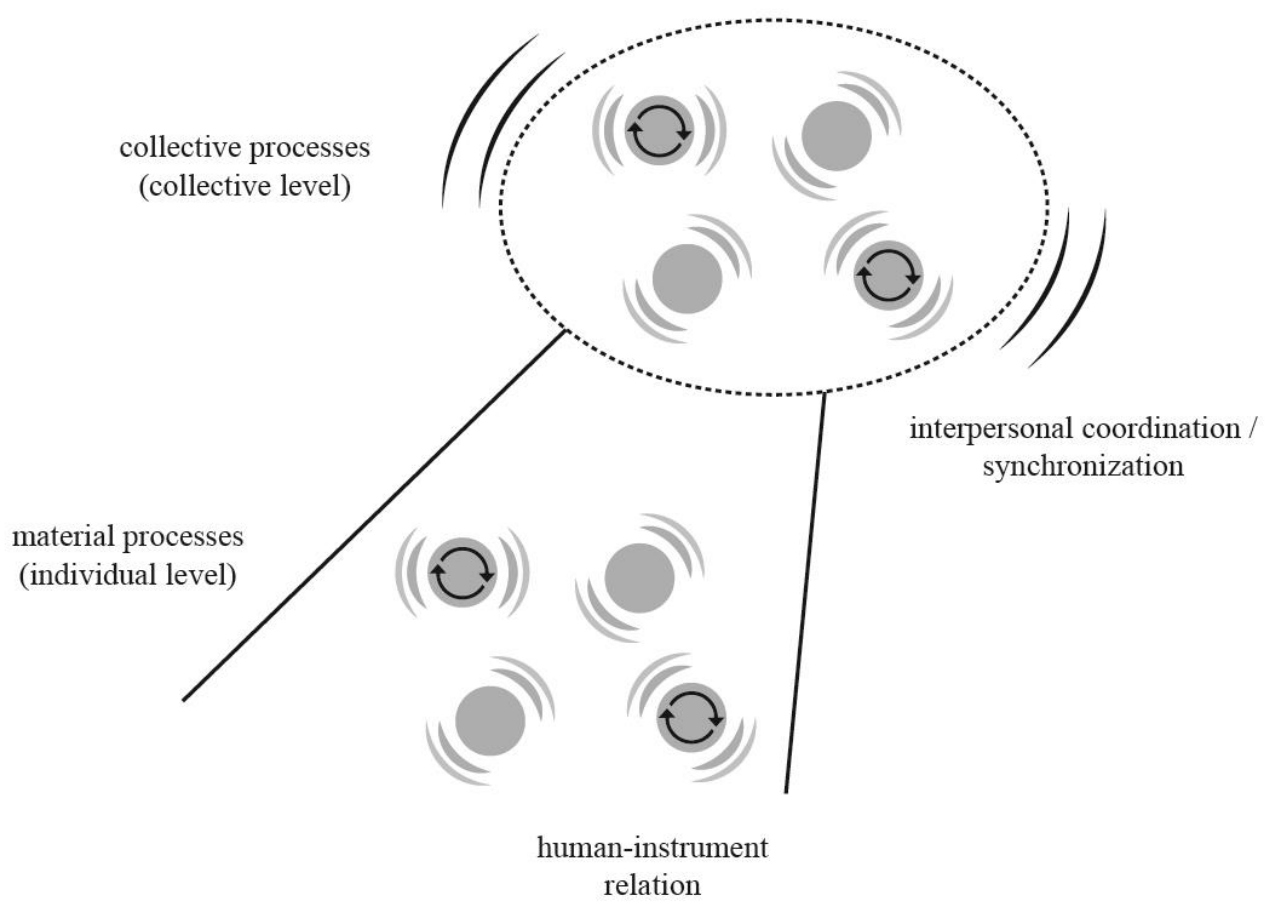

